\title{
El FOTOLIBRo EN ESPAÑA EN LOS COMIENZOS DEL SIGLO XXI: DE LA AMENAZA DIGITAL A LA APRECIACIÓN GENERALIZADA
}

\section{The Photobook in Spain at the Beginning of the 21st Century: From the Digital Threat to the Generalized Appreciation}

\author{
Mtr. Juan GIL SEGOVIA \\ Profesor Asociado. Universidad Complutense de Madrid, España. \\ E-mail: jugil01@ucm.es \\ (iD) https://orcid.org/0000-0002-1525-4463
}

Fecha de recepción del artículo: 01/09/2019

Fecha de aceptación definitiva: 23/10/2019

\begin{abstract}
RESUMEN
La situación actual del fotolibro, tanto en España como en otros países, es de una asombrosa fortaleza. Esto es debido a que se ha podido constatar una expansión sin precedentes de este formato. Si bien es cierto que las publicaciones siempre han sido un apreciado vehículo para la puesta en circulación de fotografía, la tecnología digital pareció amenazar los soportes tradicionales, derivando la fotografía hacia formas virtuales de producción y difusión. Sin embargo, paradójicamente y tras unos años de cambios vertiginosos, el fotolibro o libro de fotografía es hoy un medio altamente apreciado. En el presente artículo se analiza la situación actual del fotolibro y se plantea la hipótesis de que su auge no es una moda, sino que es su consagración como obra definitiva.
\end{abstract}

Palabras clave: Fotolibro, fotografía, libro, digital, publicación, autoedición.

\begin{abstract}
The current situation of the photobook, both in Spain and in other countries, is very strong. This is due to the fact that there has been an unprecedented expansion of this format. While it is true that publications have always been an appreciated vehicle for putting the photography into circulation, the digital technology seemed to threaten traditional media, deriving the photograph to virtual forms of production and dissemination. However, paradoxically and after a few years of vertiginous changes, the photobook or photography book is today a highly appreciated medium. In this article the current situation of the photobook is analyzed and the hypothesis is raised that its boom is not a fad, but that it is its consecration as a definitive work.
\end{abstract}

Key words: Photobook, photography, book, digital, publication, self-publishing. 


\section{Introducción}

La aparición y popularización de la tecnología digital ha provocado numerosos cambios en prácticamente todos los ámbitos. Estas modificaciones han sido especialmente relevantes en lo que se refiere a la creación y distribución de fotografías y archivos audiovisuales. Los soportes impresos, desde sus inicios, han sido excepcionales vehículos para la circulación de imágenes y parece que continúan siéndolo, pese a todo, dada la robusta salud de la que goza el fotolibro en los últimos años.

A pesar de los numerosos cambios a los que hacemos referencia, hoy en día resulta difícil sostener la teoría de la sustitución de cualquier clase de medio o soporte técnico por sistemas digitales, ya que estos, incluso aceptando su masiva implantación, están exentos de determinadas características que sí poseen otra clase de formatos. En el ámbito concreto que aquí nos ocupa, se pone de relieve tanto la especificidad como la sugerencia, así como la versatilidad, del libro impreso, erigiéndose como vehículo óptimo para la imagen fotográfica, aportando referencias y opiniones sobre el tema que cimentan la idea de la viabilidad del libro como como soporte artístico en la actualidad.

Como hipótesis principal, apuntamos que estas características son los puntos clave en los cuales reside la fortaleza actual del fotolibro, que le auguran un futuro prometedor, incluso en (o precisamente por darse en) un contexto dominado mayoritariamente por la imagen digital. En este sentido, es necesario remarcar que la supuesta moda que se vive actualmente en torno al fotolibro probablemente no sea tal, sino que, más bien, es una toma de conciencia sobre el potencial de este formato. Una consideración que ha emergido, de manera un tanto paradójica, gracias a la evanescencia y la volatilidad características de la imagen digital.

No obstante, la historia de las imágenes como parte esencial de las publicaciones es larga, pudiendo situar su máximo esplendor con la incorporación a estas de la fotografía. De la imaginería basada en el grabado y la reproducción de dibujos se pasó a la imagen tecnológica, con estados intermedios como los grabados con imágenes copiadas de fotografías u otras conseguidas a partir de la técnica del fotograbado. Con ello, además, se transitó paulatinamente del predominio del texto al de la imagen, del concepto de prensa ilustrada al de prensa gráfica.

En España, en concreto, tanto el uso del fotograbado (aunque de tardía aplicación en nuestra geografía) como la progresiva incorporación de imágenes fotográficas a la prensa modificaron radicalmente la labor periodística, produciéndose durante el siglo XIX un importante florecimiento de revistas y publicaciones en las que la imagen jugó un papel fundamental (Sánchez Vigil, 2013, pp. 70-72).

No obstante, la imagen fotográfica también se expandió de forma paralela mediante otros sistemas, como las tarjetas postales o las de visita, en su momento muy populares. Estas últimas fueron el primer gran éxito de la fotografía; retratistas ambulantes o de estudio realizaban una o varias tomas de la persona en cuestión, la cual luego utilizaba estas imágenes como carta de presentación. Estas fotografías se intercambiaban y coleccionaban. Las tarjetas postales, en cambio, representaban desde paisajes y monumentos hasta espectáculos, vedettes y deportistas.

Con el avance del siglo XX la imagen fotográfica llegó a todos los rincones del planeta, principalmente a través de los diferentes tipos de ediciones impresas: periódicos, revistas, libros, álbumes, guías, folletos, catálogos o libros de fotografía, entre otras. En este contexto, el estatuto del fotolibro dentro del espectro de publicaciones 
es notablemente específico, ya que se trata de ediciones que prácticamente no contienen texto, en muchas ocasiones tan solo el título y la autoría, siendo la imagen el elemento protagonista de manera indiscutible e independiente. Además, su carácter artístico y las tiradas generalmente limitadas hacen que el fotolibro se encuentre más cerca de una edición de obra gráfica que de un libro al uso (como una novela, por ejemplo), por más que las características físicas del objeto libro puedan remitirnos al ámbito literario.

\section{La imagen, el libro y la tecnología digital}

Sin embargo, en el siglo XXI, la expansión sin límite de la tecnología digital ha provocado nuevas dinámicas y otras formas de elaboración y distribución de contenidos. A los soportes tradicionales se unen ahora los virtuales, los cuales aportan una serie de posibilidades nada desdeñables: potentes programas de edición de imágenes y textos, enriquecimiento de la narración mediante recursos como los hipervínculos o nuevos canales (tales como redes sociales, páginas web y blogs) con una importante audiencia potencial, entre otras.

Pero es necesario que seamos conscientes de que no todo es positivo, ya que las nuevas tecnologías han expuesto casi cualquier clase de contenido al fenómeno de la piratería y ha propiciado la aparición de nuevos problemas, tales como una profunda crisis en el ámbito de los derechos de autor, la sobreabundancia de información (una información, además, de credibilidad dudosa en no pocos casos) o el surgimiento de adicciones a los teléfonos móviles. Igualmente, la supuesta desmaterialización asociada con lo digital en realidad no es tal, ya que siempre existe la mediación de alguna clase de dispositivo físico, generalmente, además, presa de la obsolescencia programada.

En el ámbito concreto del libro habría que remarcar que Internet también ha propiciado la aparición de multitud de plataformas destinadas a la divulgación y/o comercialización de publicaciones impresas: tiendas e imprentas on line, blogs de opinión o espacios que posibilitan el fenómeno del crowfunding, gracias al cual muchos proyectos han conseguido financiarse. La aparición de los recursos digitales, al favorecer los servicios de impresión y distribución de publicaciones, ha desembocado en un aumento sin precedentes de la autoedición. En España, esta práctica comienza a crecer de manera importante en torno al año 2006, principalmente porque «El modelo digital produce un efecto de desintermediación en el cual solo los dos elementos extremos de la cadena de valor del libro son imprescindibles: el autor y el lector» (Gómez, García, Cordón y Alonso, 2016, p. 193). Una situación que se ha visto fomentada por la revalorización social de la autoedición, despojada de los prejuicios que sobre ella recaían en otros tiempos.

En este poliédrico contexto, los libros digitales o electrónicos se han ido implantando con una notable lentitud (especialmente en comparación con los nuevos sistemas de distribución de contenidos musicales, por ejemplo) representando a finales de 2018 menos de un tercio (el 30,6\%) de la producción editorial total (hoy Es Arte, 2018). Estos datos quedan muy lejos de algunos vaticinios efectuados no hace tanto tiempo. Por ejemplo, en 2010, Juan González de la Cámara auguraba que «En 2011 el eBook superará al libro tradicional y en 2020 copará el 90\% del mercado» (citado en Arjona, 2010, p. 9). Y es que, tras unos años de euforia generalizada con todo lo 
relacionado con Internet y la tecnología digital, en los que parecía que los soportes virtuales iban a sustituir a todos los preexistentes, la situación en la actualidad parece otra. Siguen existiendo 'apocalípticos e integrados', en palabras de Humberto Eco, pero el escenario que parece vislumbrarse es el de una realidad compleja en la que Internet y la tecnología digital lo inunda todo mientras aparecen hoteles y locales de ocio sin conexión wifi como reclamo, al tiempo que observamos como los libros en papel, la fotografía química o los discos de vinilo no solo no desaparecen, sino que se convierten en tendencia.

Por lo tanto, parece obvio que ambos soportes (virtual y físico, analógico y digital) pueden convivir pacíficamente, ya que cada uno posee su propia especificidad: los canales virtuales de distribución de la información plantean nuevas dinámicas de creación y distribución, ya que el blog, la página web o la red social no tienen los límites que pueden tener una novela en papel o una fotografía enmarcada. Sin embargo, lo digital carece de ciertos matices que, como el tipo de papel o la calidad de la impresión, si poseen las publicaciones físicas, además de no necesitar ninguna fuente de energía para "funcionar".

Del mismo modo, la lectura (tanto de imágenes como de textos) no es igual en un medio o en otro, aunque lo leído sea lo mismo: en soporte papel este invita, en general, al recogimiento, mientras que en lo digital se fomenta la interacción, entre otras cosas por los hipervínculos antes mencionados o los anuncios que vemos en cada una de nuestras incursiones en la red. Esto no quiere decir que un soporte u otro sean mejor o peor, simplemente son diferentes y se puede recurrir a uno u otro en función del momento, la situación o la obra.

Además, hoy en día, es perfectamente posible que en el desarrollo de un trabajo destinado a editarse en soporte papel se materialice gracias a una imprenta digital, se publicite en las redes sociales y se distribuya de forma on line, por ejemplo, por lo que mantener una guerra de formatos y soportes parece actualmente una estrategia un tanto inútil.

Pero, además, existen otras cuestiones relevantes que debemos abordar si hablamos del libro como soporte en la actualidad, como por ejemplo la cuestión ecológica. En el momento de emergencia climática en el que nos encontramos resulta de importancia capital apostar por las opciones menos contaminantes, y las digitales no necesariamente lo son. Esto se debe a que la tendencia a mudar de dispositivo tecnológico con una frecuencia muy alta provoca que los efectos medioambientales su producción se multipliquen, algo a lo que hay que sumar que el reciclaje de estos dispositivos no siempre se realice de manera adecuada, terminando muchos de ellos en vertederos del tercer mundo y contaminando ambientes naturales. Por el contrario, el uso de papel reciclado y tintas ecológicas minimiza el impacto medioambiental de la producción de libros, además de, como hemos mencionado, una obra en soporte papel ya producida no necesita ninguna fuente de energía y, por lo tanto, ya no consume recursos naturales, al contrario que un libro electrónico.

\section{El fotolibro}

El fotolibro es una publicación en la que la imagen fotográfica es el elemento más significativo, cuando no el único. Dentro de esta definición podrían caber desde guías de viaje hasta catálogos de exposiciones, aunque generalmente se entienden como 
publicaciones concebidas como obras de arte autónomas, en las que «Las imágenes forman un relato, una sucesión de estímulos ordenados» (Fernández, Gimeno, Uriarte y de Middel, 2014, s. p.).

Un fotolibro dista mucho, por ejemplo, de un conjunto de imágenes colgadas en una red social. El libro, por su propia estructura, tiene un principio, un desarrollo ( $\sin$ normas estrictas respecto a su carácter y duración) y un final, mientras que en las redes sociales el planteamiento es mucho más flexible: hay un principio, pero no un final, siempre se pueden publicar más imágenes, borrar todas o algunas de las ya publicadas y el resto de los/as usuarios/as las pueden comentar y compartir. En un fotolibro es de importancia capital que sea una obra cerrada, que quede inalterada una vez terminada, siguiendo fiel a la idea de su autor/a, aunque este/a desaparezca. Por ello el soporte papel quizá sea el mejor vehículo para estos trabajos.

En su diseño juegan un papel relevante varios factores: el gramaje de papel, el tipo de impresión, la cubierta, el formato, la tipografía, la selección de las imágenes y el orden de estas, además del diseño y la maquetación. Del mismo modo también son importantes otras cuestiones como los vacíos, ya que los espacios en blanco (como los silencios en la música) influyen de manera decisiva en el ritmo de lectura/visionado. Esto es algo que se encuentra prácticamente ausente en el ámbito digital, dominado por otra clase de dinámicas, con mayor tendencia al exceso y al abigarramiento. En torno a estas decisiones puede haber un equipo numeroso de personas o, por el contrario, muy escaso, siendo únicamente imprescindibles, en último término, los dos extremos de la cadena productiva: el/la autor/a y el/la impresor/a.

El fotolibro nace prácticamente con la fotografía misma. Uno de los primeros fotolibros de la historia es 'Photographs of British algae. Cyanotype impressions' de Anna Atkins (1843), una obra del ámbito de la botánica realizada mediante el proceso de la cianotipia. La publicación se limitó a unos pocos ejemplares autoeditados por Atkins, en un ejemplo seminal de do it yourself. Según Cuevas (2017) se trata de «Un libro que para algunos no era un libro porque, al no centrarse en la palabra escrita, rompía unas reglas que nadie había escrito". La importancia de esta obra ha llevado a que cada aniversario de su adquisición por parte de la biblioteca del British Museum (14 de octubre de 1843) se celebre el día internacional del fotolibro' ${ }^{1}$. Tan solo un año después de la edición de este libro se comenzaría a publicar 'The Pencil of Nature' de William Henry Fox Talbot, «el primer libro importante ilustrado con fotografías originales» (Johnson, Rice y Williams, 2010, pp. 90-91), que vio la luz en seis entregas entre 1844 y 1846. La obra incluye 24 calotipos que reproducen imágenes de distintas temáticas, se publicaron un total de 130 series de las cuales solo una docena han llegado hasta nuestros días (Sánchez Vigil, 2007, p. 441.).

Desde entonces el concepto de "libro de fotografía» no ha parado de crecer, tanto en el ámbito público como en el privado; por un lado, la fotografía estaba cada vez más presente en cualquier clase de publicación y, por otro, las familias comenzaron pronto a atesorar retratos y otras imágenes para nutrir álbumes familiares, a los que podemos considerar como una variante particular del libro de fotografía. Sin embargo, la volatilidad del propio soporte y las tiradas limitadas de muchas de estas publicaciones dificultan su conservación y, por lo tanto, su consideración histórica. Esto ocurre

1. Más información: https://photobookday.wordpress.com/ 
especialmente en países como España, en el que este medio no ha sido excesivamente valorado hasta fechas muy recientes.

Además, el libro como vehículo para la fotografía ha tenido que superar ciertas reticencias hasta llegar a su positiva aceptación actual, tal y como apunta Fernández:

De aceptar la rutina, las fotos que merecen la atención deben ser únicas y sintéticas, es decir, una historia en una imagen, un relato que debe ser completado por el espectador, tal y como ha sugerido Julio Cortazar. Esta creencia tiene fundamento, se sustenta en un hecho innegable: muchos fotógrafos han dedicado su carrera a conseguir síntesis de imagen - historia, cazándolas por aceras sombrías o cultivándolas en invernaderos con calefacción. Pero también es verdad que otros fotógrafos no menos numerosos prefieren modelos como el ensayo, la serie o el libro, es decir, los procedimientos en los que el relato precisa imágenes ordenadas con ciertos propósitos (2011, p. 11).

Aunque las obras de Atkins o Talbot tienen un indudable valor artístico podríamos decir que el fotolibro como medio creativo comienza a consolidarse (sin menospreciar por ello iniciativas anteriores) en las décadas posteriores a la II Guerra Mundial, con obras que nacen tanto en el ámbito del fotoperiodismo como en el mundo del arte. La sumisión del reportaje fotográfico de encargo a los deseos del editor, al texto del redactor y a la industria en general provocaba, a menudo, que el fotógrafo no quedara satisfecho con el resultado de las imágenes. Esto empujó a muchos/as autores/as a buscar otras vías de visibilización de su trabajo, con un mayor control sobre el resultado final. Algunos fotolibros importantes de esta época son 'The decisive moment' (1952) de Henri Cartier-Bresson, 'New York' (1956) de William Klein o 'The lines of my hand' (1972) de Robert Frank, uno de los fotógrafos de mayor prestigio de todos los tiempos y que ya había publicado su aclamado libro 'The Americans' (1958-59).

En aquellos momentos los artistas estaban volviendo su mirada de manera generalizada (aunque desde distintos posicionamientos -el pop art, el minimalismo o el arte conceptual-) hacia los medios masivos de producción y comunicación, buscando, como en el caso de 'Twenty-six Gasoline Stations' (1963) de Ed Ruscha, «superar el esteticismo fotográfico que había sido protagonista durante las décadas anteriores» (Gómez Isla, 2005, p. 41). Con el tiempo, al igual que 'The Americans', este desapasionado catálogo de estaciones de servicio situadas en el trayecto entre Oklahoma y Los Ángeles se ha convertido en una obra paradigmática de esta época y de la historia del fotolibro. Ruscha autopublicaría posteriormente otras obras icónicas como 'Some Los Angeles Apartments' (1965), que es, literalmente, una colección de imágenes anodinas de 'algunos apartamentos de Los Ángeles', o 'Every Building on the Sunset Strip' (1966), una publicación que consta de una única página desplegable con dos fotografías panorámicas (una de cada lado de la calle) en la que se ven 'todos los edificios de Sunset Strip'.

Estas obras nos introducen en una de las variantes que más a fondo se ha abordado desde el ámbito del fotolibro: la que trabaja con el concepto de archivo. Este y la inclinación por las publicaciones de artistas parecen estar unidos, en palabras de Glòria Picazo:

Este interés por la edición se complementa a menudo por la atracción que el archivo ha suscitado en muchos artistas, un tema crucial que ha significado bastantes, por no decir muchos, proyectos de arte contemporáneo [...]. La fotografía será un medio sumamente idóneo para llevar a cabo estos propósitos, y así ya sean fotografías realizadas por los 
propios artistas o apropiadas a partir de lo publicado en medios de comunicación y rescatadas de bibliotecas, archivos y hemerotecas (2018, p. 178).

Algunos libros paradigmáticos en este sentido son 'Anonyme Skulpturen' (1970), de Bern \& Hilla Becher, 'Side by side' (1972), de Gilbert \& George, 'Relojes' (1973), de Isidoro Valcárcel-Medina, 'Autobiography' (1980), de Sol Lewitt, 'Some Disordered Geometries' (1981), de Francesca Woodman, 'Photographs' (1989), de Peter Fischli \& David Weiss, 'The ballad of sexual dependency' (1996), de Nan Goldin o 'Die toten (1967-1993)' (1998), de Hans-Peter Feldmann.

Desde entonces el fotolibro se ha ido incorporando al repertorio creativo de muchos/as autores/as, favoreciendo la normalización de este medio hasta que

En los últimos años, la importancia de los fotolibros es cada vez más reconocida en exposiciones y publicaciones. Una cuestión de reciente actualidad, ratificada por los precios al alza del mercado, tan sensible como de costumbre a los cambios de tendencia. [...] Las exposiciones, el otro sistema principal de ver fotografías, son mucho menos manejables: viajan mal, duran poco tiempo, llegan a menos gente. En los libros circulan mejor las ideas y la información (Fernández, 2011, p. 13).

\section{Las publicaciones de fotografía en España}

Durante el siglo XIX español, de manera general, se fue implantando lentamente la incipiente modernidad que se vivía en otros países europeos. En el caso de la introducción de la fotografía en España, en concreto, el revolucionario invento fue recibido en muchos ambientes "más como una ocurrencia de feria que como una conquista del desarrollo tecnológico» (Goikoetxea, 2009, p. 20). Una de las consecuencias de esta actitud fue, entre otras, que muchos de los primeros estudios fotográficos que se abrieron en suelo español estuvieron gestionados por profesionales extranjeros. Estos habrían venido a cubrir un vacío existente en la oferta, aunque no así en la demanda, como demostraría el tiempo.

Sin embargo, a título histórico hay que apuntar que, junto al trabajo de Anna Atkins y William Henry Fox Talbot, otra de las publicaciones pioneras en el ámbito de la fotografía se gestó en España: 'Annals of the Artists of Spain', el primer libro de arte de la historia ilustrado con fotografías (Sánchez Vigil, 2007, p. 107). Aunque fue editado por el erudito escocés William Stirling Maxwell en 1847-48, su origen español se debe a que reproduce numerosas obras de la colección del Museo del Prado. Se trata de una obra compuesta por cuatro volúmenes, los tres primeros escritos por el propio Stirling Maxwell y un tomo anexo con reproducciones de obras de artistas españoles de los siglos XVI y XVII y de Goya. El procedimiento fotográfico fue el calotipo (también llamado talbotipo en honor a su inventor, el científico inglés Fox Talbot), mediante el cual se obtuvieron casi setenta reproducciones realizadas por el fotógrafo Nicolaas Henneman, antiguo ayudante de Talbot. En su momento solo se editaron 50 ejemplares, de los que se conservan la mitad. Este libro y su complejo proceso de edición fueron objeto de una exposición en el Museo del Prado, dentro del festival PHotoEspaña, en 2016 titulada 'Copiado por el sol'.

Tras la expansión de los estudios fotográficos, durante las dos primeras décadas del siglo XX se produjo en España una considerable eclosión de las revistas especializadas y, como consecuencia de estas, del amateurismo. La fotografía de desnudo, 
por ejemplo, fue practicada entonces más por aficionados que por profesionales, que vieron ciertas oportunidades de negocio en ello. De esta forma comenzaron a aparecer publicaciones sicalípticas en España, profusamente ilustradas con fotografías (generalmente de autoría anónima), como 'La Saeta', 'Vida Galante', 'La Hoja de Parra', 'Las mujeres en la intimidad' o 'Portafolio del desnudo' (López Mondejar, 1999, p. 136). En cambio, al mismo tiempo y dada la ductilidad de la imagen técnica, en los círculos intelectuales «La fotografía era una forma más de acercarse al progreso que vivían otros países. Hija de la ciencia humana, ningún mecanismo parecía mejor o más exacto para la documentación y demostración» (González, 2007, p. 207).

En los diarios españoles no fue hasta el año 1904 cuando comenzaron a incluirse fotografías, en concreto fue en la cabecera certeramente llamada 'El Gráfico' (Sánchez Vigil, 2006, p. 59). Mientras esta tendencia se generalizaba en la prensa española, el público se familiarizaba con la fotografía mediante series coleccionables como 'Portafolio Fotográfico' o 'España Artística' y, especialmente, a través de las tarjetas postales, cuya mayor cuota de popularidad en nuestro país se sitúa entre los años 1900 y 1925 (López Mondejar, 1999, p. 138), surgiendo un notable coleccionismo de este tipo de imágenes. Al respecto, afirma López Mondejar (1999, p. 139) que en la sociedad de la época «enviar y recibir postales se convirtió en la afirmación de un cierto status social y cultural».

Posteriormente, tanto durante la guerra civil como en los años inmediatamente anteriores, las publicaciones jugaron un papel muy importante en el devenir histórico, ya que fueron utilizadas con fines políticos de manera generalizada, como reflejo del momento de ebullición social que se vivía. Testigos de aquella época convulsa y del papel que jugó en ellos la imagen fotográfica fueron las exposiciones 'Fotografía pública. Photography in Print. 1919-1939' (del 27 de abril al 29 de junio de 1999 en el Museo Reina Sofía de Madrid), 'Una luz dura, sin compasión. El movimiento de la fotografía obrera. 1926-1939' (del 6 de abril al 22 de agosto de 2011 en el Museo Reina Sofía de Madrid), 'Revistas y movimiento obrero. 1926-1939' (del 24 de agosto al 30 de noviembre de 2011 en la Biblioteca y el Centro de Documentación del Museo Reina Sofía de Madrid). La primera de ellas fue comisariada por Horacio Fernández y las dos últimas por Jorge Ribalta.

Durante la posguerra, en un ambiente general de evidente carestía, la fotografía que no fuera para ser utilizada como propaganda política no era una prioridad. En este ambiente, "La edición de libros sobre fotografía en los años cuarenta y cincuenta era una ilusión, no solo por la falta de medios, sino también por el escaso interés en torno a esta materia” (Sánchez Vigil, 2013, p. 314). Durante este tiempo casi lo único y lo más destacable es el trabajo de José Ortiz Echagüe, probablemente el fotógrafo español de la primera mitad del siglo XX con mayor proyección internacional. En su obra destaca la publicación de libros como 'España: Pueblos y paisajes' (1939), 'España mística' (1943) o 'Tipos y trajes de España', editado por Espasa Calpe en 1930 con prólogo de Ortega y Gasset (Vega, 2017, p. 602). El trabajo de Ortiz Echagüe ha sido relacionado con el pictorialismo, aunque él se consideraba «un documentalista de su tiempo y de la realidad española de la primera mitad del siglo XX" (Meseguer, 2008, p. 90).

A partir de la década de 1950 las revistas vuelven a tener una influencia capital en el desarrollo de la fotografía en España. En esta época se publican 'Sombras' (entre 1944 y 1954), el boletín 'Afal' (publicada por la Agrupación Fotográfica Almeriense entre 1956 y 1962), 'Arte Fotográfico' (que lleva editándose desde 1952, lo que la 
convierte en la publicación más longeva de la fotografía española) e 'Imagen y Sonido' (1963-1980). 'Sombras' y 'Arte Fotográfico' representan una visión clásica de la fotografía y un especial apego a las asociaciones y salones fotográficos. No obstante, pese al conservadurismo de estas publicaciones es justo reconocer sus aportaciones a la fotografía española. 'Arte Fotográfico', en concreto y por poner un ejemplo, intentó traer a España (aunque desgraciadamente sin éxito) la mítica exposición 'The Family of Man', organizada por Edward Steichen para el MOMA de Nueva York y que estuvo itinerando por distintos países entre 1955 y 1964 (Vega, 2017, p. 515). Entre estas publicaciones, el boletín 'Afal' sería sin duda el más aperturista.

En los años 60 sobresale la muy recordada colección 'Palabra e Imagen', publicada por la editorial Lumen. Tal y como indica el título de esta iniciativa, la idea era combinar textos de conocidos escritores con la fotografía de relevantes autores/as, generando combinaciones excepcionales como las de Camilo José Cela y Joan Colom, Miguel Delibes y Ramón Masats o Juan Benet y Colita. En esta época otras editoriales comenzaron a apostar tímidamente por los libros de fotografía, entre estas publicaciones podemos destacar 'Los Sanfermines' de Ramón Masats (Espasa, 1963), 'España Clara' de Nicolás Muller (Doncel, 1966) o 'Costa Brava Show' (Kairós, 1961) y 'Barcelona Blanc i Negre' (Aymá, 1964), ambos de Xabier Miserachs.

En la década de 1970 comienza una época de renovación en prácticamente todos los contextos del país, incluida la propia fotografía. En este ámbito en concreto, según Sánchez Vigil (2013, p. 374), «El boom de libros y revistas se produjo en el último cuarto de siglo». Punta de lanza de esta explosión fue la revista 'Nueva Lente', por su impacto y por su carácter seminal. A partir de 1971 inició una revolución en el panorama fotográfico español, ya que se trataba de «Una publicación con un tono anárquico y tintes contraculturales que incentivaba la imaginación y el experimentalismo» (Fontcuberta, 2000 , p. 131). Recordemos que la revista, aunque se publicaría hasta el año 1983, vivió su primera etapa durante los últimos estertores del franquismo, una época (1971-1975) en la que, según el historiador Publio López Mondejar, se caracterizó por «una actitud puerilmente provocadora, que decretaba el agotamiento de la realidad como materia fotográfica» (1999, p. 246). Como puede verse, el carácter rompedor de 'Nueva Lente' no provoca indiferencia, no obstante, siendo justos, "Conviene resaltar, sobre todo, el papel desempeñado por la revista como aglutinador de las diferentes tendencias de vanguardia de principios de los 70» (Vega, 2017, p. 626).

Pero en esta década no solo existía 'Nueva Lente'. Mientras ‘Arte Fotográfico' continuaba publicándose (con prácticamente el mismo espíritu con el que había nacido dos décadas atrás) vería la luz el primer anuario 'Spafoto' (1972), en 1973 aparecían otros dos anuarios ('Coteflash' y 'Everfoto'), al año siguiente se publicaba el primer número de la revista 'Flash-Foto' y, ya en 1976, Photocentro edita la versión española de la revista francesa 'Zoom'. En la década siguiente aparecieron, entre otras, 'PhotoVision' (1981), 'Foto Profesional' (1983), 'La Fotografía' (1986) o 'FV' (1989). En 1990, la Sociedad de Historia de la Fotografía Española comienza a publicar la 'Revista de Historia de la Fotografía Española', en 1995 ve la luz 'Archivos de Fotografía', gracias al Photomuseum de Zarautz, y en 1996 'Papel Alpha-Cuadernos de Fotografía', editada por el Centro de Fotografía de la Universidad de Salamanca. Estas últimas son algunas de las revistas de fotografía que iniciaron su andadura en la década de los noventa del siglo XX, junto a otras como 'Matador' (1995), editada por La Fábrica (empresa privada responsable también del festival PHotoEspaña, desde 1998). Ya en el siglo XXI aparecen 'Exit' (2000), dirigida por Rosa Olivares, 'Rojo' (2001), dirigida en este caso 
por David Quiles Guilló, o ‘C Photo Magazine’ (2005), editada por Elena Ochoa, entre otras referencias.

Volviendo a los libros de fotografía, quizá lo más relevante del siglo XX español se concentra, además de en el trabajo de José Ortiz Echagüe y la colección 'Palabra e imagen', en el tramo final de la centuria. Pese al tiempo transcurrido y los cambios acaecidos durante el paso del mismo parece existir una cierta continuidad temática. En concreto nos referimos al impulso documentalista de una sociedad en trance de desaparecer, la cual era el eje vertebrador del trabajo de Ortiz Echagüe y que Cristina García Rodero actualiza en extraordinarias obras como 'España oculta' (Doctor, 2013, p. 132) publicada en 1989. La visión de un país que, aun hoy, se debate entre tradición y modernidad, marcando un punto inflexión en este sentido y tratando de renovar la visión de este fenómeno dada en el pasado igualmente se puede apreciar en otros trabajos como 'España, fiestas y ritos' (1992), también de García Rodero, ‘ 4 cosas de España' (1990), 'Lances de aldea' (1992) y 'Vanitas' (1998) de Cristóbal Hara, 'Vestigios' (1990) de Fernando Herráez, las series ‘España mágica', 'Los Sanfermines' o 'El nacimiento de una nación', de Koldo Chamorro (reunidos en la monografía 'Koldo Chamorro' en 1998) o 'Imágenes gitanas' (1995), de Ramón Zabalza (López Mondejar, 1999, p. 259).

A estos acercamientos a los ritos, festejos y tradiciones que pueblan los rincones de España se unen las narrativas urbanas, ejemplificadas en libros como 'Bikers' (1993) o 'Los malheridos, los bien amados, los traidores' (1993), de Alberto García-Alix (fruto de su pasión por el mundo de las motos), o la publicación 'Guirigato' (2001), de Luis Baylón, cuyo título es un juego de palabras entre el apelativo coloquial que se suele dar a los extranjeros en España (guiris) y a los madrileños como él (gatos) y que aglutina imágenes tomadas en Madrid, Zamora, Portugal, Marruecos y La India entre finales de los ochenta y el año 2001. Por último, reseñar que en los años noventa nacen editoriales como Actar, Tf, Mestizo, La Fábrica o la colección 'Campo de Agramante' de la Universidad de Salamanca, que se suman a otras ya existentes como Lunwerg, Blume, El Viso o Espasa.

\section{El fotolibro en la España del siglo XXI}

La situación actual del fotolibro, tanto en España como en otros países, es de una asombrosa fortaleza. Esta afirmación se sustenta en la expansión sin precedentes del formato que se ha podido constatar en los últimos años. En contra de lo que sucede normalmente, esta vez lo que ocurre en España lo hace en paralelo, con tanta o incluso mayor fuerza y al mismo tiempo que en otras partes del mundo.

«A principios del nuevo siglo se publicaban muchos libros con fotos, pero muy pocos fotolibros» (Museo Nacional Centro de Arte Reina Sofía, 2013). Podíamos leer esto en la hoja de sala de la exposición 'Libros que son fotos, fotos que son libros' (del 17 de diciembre de 2013 a septiembre de 2014 en la Biblioteca y el Centro de Documentación del Museo Reina Sofía de Madrid) y, a la vista de esta afirmación, del contexto en el que se realiza y lo ocurrido desde entonces podríamos decir que el fotolibro ha pasado de la insignificancia al Museo en un espacio de tiempo muy corto.

Según Celia Vega (2016, p. 30), el auge internacional del fotolibro comienza en torno al año 2009: 
En un momento en el que parece lógico que la creación fotográfica actual tenga como soporte la pantalla, el fotolibro se postula como el candidato perfecto para difundir la obra de los (post)fotógrafos. Esto se explica, además de por cuestiones técnicas -abaratamiento de los costes de producción, impresión digital, sistema de print-on-demand...por las características formales del libro.

Este auge se ha ido produciendo en paralelo a (y se ha visto potenciado por) la edición de los tres tomos de la publicación de referencia en el ámbito del fotolibro: 'The Photobook. A History', de Martin Parr y Gerry Badger (Phaidon, 2004, 2009 y 2014).

Además de la citada muestra 'Libros que son fotos, fotos que son libros', en los últimos años se han celebrado en España otras exposiciones dedicadas en exclusiva al libro de fotografía, tantas como en ningún otro momento y con especial atención a la producción reciente de fotolibros, tales como 'Fotolibros. Aquí y ahora' (del 13 de mayo al 30 de julio de 2014 en la Fundación Foto Colectania de Barcelona), 'Nueva York en Fotolibros' (del 7 de abril al 11 de junio de 2017 en el Centro de Fotografía Contemporánea de Bilbao y anteriormente en el Centro José Guerrero de Granada) o 'SCAN Photobooks', una muestra anual (desde 2013) de fotolibros dentro del Festival de Fotografía SCAN, celebrado en Tarragona. Esta recuperación del fotolibro puede encuadrarse dentro de otra de carácter más global, como es la que está viviendo el libro de autor/a (o libro de artista) en general. Esta tendencia también puede ejemplificarse mediante varias exposiciones realizadas en España en los últimos años como 'Bibliotecas insólitas' (del 16 de junio al 10 de septiembre de 2017 en La Casa Encendida de Madrid y del 30 de enero al 23 de abril de 2018 en Arts Santa Mónica de Barcelona) y 'Libros (y otras publicaciones) de artista (1947-2013)' (del 23 de julio al 30 de agosto de 2014 en la Fundación Juan March de Madrid), u otras como 'Lo nunca visto. De la pintura informalista al fotolibro de postguerra (1945-1965)' (del 26 de febrero al 5 de junio de 2016, también en la Fundación Juan March de Madrid), la cual pone en relación las publicaciones fotográficas de una determinada época con otras manifestaciones artísticas como la pintura.

Sin embargo, las exposiciones recientes más relevantes relacionadas con el fotolibro quizá sean: 'Fenómeno Fotolibro', (del 18 de marzo al 25 de junio de 2017 en el Centro de Cultura Contemporánea de Barcelona y la Fundación Foto Colectania de Barcelona), 'Fotos \& libros. España 1905-1977' (del 28 mayo de 2014 al 5 de enero de 2015 en el Museo Reina Sofía de Madrid y posteriormente en el Museo Amparo de Puebla, México, entre el 16 abril y el 15 agosto de 2016) y 'Revelaciones. Historia del fotolibro en Latinoamérica' (del 5 de junio al 14 de julio de 2012 en Ivorypress Art + Books, Madrid). Esta última muestra es la versión expositiva de la publicación 'El Fotolibro Latinoamericano' (editorial RM, 2011) de Horacio Hernández, el mayor experto español en torno al fotolibro, y está formada por una selección de títulos publicados desde 1920 hasta el siglo XXI en 11 países latinoamericanos. Esta última exposición, además, tras haber inaugurado su andadura en París recalaría después en Estados Unidos y varios países de América Latina.

El propio Fernández admite que el fotolibro está empezando a ser reconocido, tras una longeva andadura:

La obra principal de la mayoría de los fotógrafos reconocidos tiene forma de fotolibro. Sin embargo, la institución arte (museo, mercado, academia) no presta suficiente atención a los fotolibros. Es posible que la situación esté cambiando y se valoren los 
fotolibros y sean aceptados en el espacio de las obras de arte como si fueran (como a veces son) obras de arte (2017, s.p.).

La presentación de estas «obras de arte» en las exposiciones es algo sobre lo que debemos detenernos brevemente, puesto que no son piezas al uso. La problemática reside principalmente en que es un formato que no está concebido para exponerse. Esto no quiere decir que sea imposible mostrarlas públicamente, sino que debe cuidarse la presentación teniendo en cuenta sus particularidades. En la muestra 'Una luz dura, sin compasión. El movimiento de la fotografía obrera, 1926-1939', por ejemplo, las publicaciones se presentaron en vitrinas (libros cerrados, con la portada visible o abiertos por una determinada página), junto a carteles y fotografías enmarcadas y material audiovisual de época. En otras exposiciones, sin el marcado carácter histórico de la anterior, los fotolibros se pueden consultar íntegramente. Esta es la forma de poder conocer y disfrutar la obra en toda su dimensión, aunque este tipo de presentación es inviable en piezas únicas o que muestren problemas de conservación. En la mencionada exposición 'Fotolibros. Aquí y ahora' se optó por posibilitar la consulta de los libros en sala y se combinó con ampliaciones de algunas de las imágenes de las publicaciones mostradas en pared.

Del mismo modo, también es necesario referirse sucintamente a otras publicaciones relacionadas con el ámbito del fotolibro, como catálogos de exposiciones, por ejemplo. En el caso de la publicación editada con motivo de la última exposición a la que nos hemos referido y titulada 'LIBRO. Un ensayo acerca del libro de fotografía y de su momento actual en España', más que de un catálogo hablamos de un fotolibro, diseñado por Eloi Gimeno con fragmentos de textos de Horacio Fernández, Cristina de Middel y Jon Uriarte, salpicados entre y sobre las imágenes. El catálogo de la también citada 'Fenómeno Fotolibro' es igualmente una publicación muy especial, formada por ocho volúmenes de 16 páginas cada uno reunidos en una caja de cartón serigrafiada. La obra fue seleccionada en el Premio PHotoEspaña 2018 al Mejor Libro de Fotografía del Año. Esta, junto al resto de piezas escogidas, formó parte de una exposición colectiva en la Biblioteca Nacional de España (Madrid) del 6 de junio al 23 de septiembre del 2018, una muestra y unos premios que ya son clásicos dentro del festival PHotoEspaña. Otra muestra más de la pasión que hay actualmente en torno a los libros de fotografía es que se han empezado a abrir clubs de fotolibros; en 2011 abrió Photobook Club Barcelona ${ }^{2}$ y en 2012 el de Madrid ${ }^{3}$, expandiéndose la iniciativa posteriormente a ciudades como Castellón, Murcia o Gijón, entre otras.

Tal y como se conceden premios, se realizan exposiciones y se abren clubs en torno al fotolibro, también han nacido en España ferias dedicadas a este formato en particular o al libro de autor/a en general. En el año 2013 es cuando comienzan a celebrarse ferias dedicadas exclusivamente al fotolibro en España, concretamente surge 'Fiebre', en Madrid, organizada por el colectivo Blank Paper, dando el salto a Barcelona en 2019, dentro del festival 'Art Photo Bcn'. Desde 2015 se celebra a primeros de junio en Madrid 'PHotoBook Week', un encuentro organizado por La Fábrica y que aglutina presentaciones, talleres, mesas redondas y una pequeña feria. No obstante, la mayoría de este tipo de eventos están dedicados al llamado "libro de autor/a», concepto más amplio que engloba a publicaciones creativas de todo tipo,

2. Más información: https://photobookclubbarcelona.com/

3. Más información: http://photobookclubmadrid.com/ 
el fotolibro incluido, pero no en exclusiva. Una de las más importantes es 'ArtsLibris', que se celebra en Barcelona desde 2009 y, desde 2016, también en Madrid, aunque en este caso dentro de otra feria, la de arte contemporáneo 'ARCO'. Este último es un modelo híbrido, ya que se trata de una feria especializada en edición dentro de una feria generalista de arte contemporáneo. En 2019, durante la cuarta edición de la feria 'ARCO Lisboa', 'ArtsLibris' ha estado presente por vez primera.

Otra feria relevante es 'Libros Mutantes' (celebrada en Madrid desde 2010), la cual, en cambio, es un evento con un espíritu más ligado al fanzine y al do it yourself:

«Es el modo más sencillo de acercarse a la autoedición y forma parte de las inquietudes de una generación muy digital que también es nostálgica y siente cariño por la revista y el libro, y que apuesta por crear algo que pueda perdurar en el tiempon, indica la comisaria. Y es ahora cuando llega el eterno debate sobre la relación entre el soporte físico y el mundo digital: «También hay fanzines 'online' y proyectos que convierten publicaciones físicas en digitales. Sin lo digital esta escena no podría funcionar, porque todo se vende y se promociona de forma 'online'»(Bianchi, 2016).

Pero 'Libros Mutantes' no está sola, ya que en los últimos años se ha vivido una autentica explosión de ferias especializadas en la autoedición y las publicaciones independientes en España: 'Más que Libros', 'Papel+', 'Pichi Fest' y 'Mea Maravilloso' en Madrid, 'Kboom', 'Ilu Station', 'Gutter Fest', 'Fun Fan Fest' y 'FLIA' (Feria del Libro Independiente Autoeditado de Barcelona) en la capital catalana junto a 'Graf', que celebra dos ediciones al año, una en Barcelona y otra en Madrid. Pero hay más, diseminadas por toda la geografía nacional: 'Bala', 'Ohete' y 'Autoeditados' en Bilbao, ‘Autobán' y 'Autobom' en A Coruña, 'Librarte' (Feria del Libro de Artista de Castilla y León) en Burgos, 'Guillotina' en San Sebastián, 'Tenderete', en Valencia, 'Grapa Grapa' en Pontevedra, ¡'EA!' (Encuentro de Autoedición) en Valladolid, 'Nosotros Feriantes' en Cuenca, 'Vermú fanzineroso' en Zaragoza, 'CoZidos' en Las Palmas de Gran Canaria, 'Zorroclos e Lobos' en Murcia, 'Fun Fun Fun!' en Santiago de Compostela, 'Dios Me Libro' en Alicante, 'La Nau Autoedició' en Terrassa (Barcelona), 'Pumpk' en Pamplona, 'Tropicana Dreams' en Mallorca, 'Inclasificables' en Salamanca, 'Muaré' en Algeciras (Cádiz), 'Edita' en Punta Umbría (Huelva), 'Entropía' en Málaga o la Feria de Autoedición 'Ciudad de Hellín' (Albacete), que se estrena en 2019.

Estas ferias y encuentros en ocasiones tienen una vida efímera, debido a que muchos de ellos se mueven en el ámbito de la autogestión, sin ninguna clase de ayuda institucional. Sin embargo, el número es lo suficientemente relevante como para constatar una importante escena. Por ello, tal y como apunta Carmelo Vega, "Aunque en ocasiones se habla con cierto desdén de la moda o la fiebre del fotolibro, convendría no menospreciar la magnitud y trascendencia que ha adquirido la autoedición de libros fotográficos en España desde el año 2000» (2017, p. 683).

En este auge de la autoedición ha tenido bastante que ver las actividades formativas que han surgido en los últimos años. Frente al inmovilismo generalizado de las enseñanzas oficiales (escuelas y facultades de Bellas Artes, por ejemplo) y la lentitud con la que actualizan los contenidos de sus planes de estudios, las escuelas privadas de fotografía han cubierto este hueco, y lo han hecho satisfactoriamente, a la vista de los resultados. Algunas de estas escuelas son: 'EFTI' (Centro Internacional de Fotografía y Cine, desde 1987), 'LENS' (Escuela de Artes Visuales, desde 2010) 
y 'PIC.A' (Escuela Internacional Alcobendas-PhotoEspaña ${ }^{4}$, desde 2013) en Madrid; 'Institut d'Estudis Fotogràfics de Catalunya' (desde 1972) y 'Grisart' (Escola Internacional de Fotografía, desde 1985) en Barcelona, junto a otros espacios como el 'Centro de Fotografía Contemporánea de Bilbao' (desde 2013) o el malagueño 'Apertura' (Centro de Fotografía y Artes Visuales, desde 1995). En este contexto también es necesario mencionar 'Siete de un golpe', taller especializado en autoedición de fotolibros, activo entre 2010 y 2014 y dirigido por el especialista Gonzalo Golpe.

La fortaleza de la edición independiente y de la autoedición en España viene dada, en parte, por la ausencia de apoyo por parte de las instituciones a la que hacíamos mención. A este respecto Uriarte apunta que:

Afortunadamente una nueva generación de fotógrafos ha dado un gran paso adelante alcanzando con sus fotolibros los más altos reconocimientos, con múltiples premios y apariciones en listas y publicaciones internacionales [...], también han sabido entender y aprovechar que, a diferencia de la exposición, el fotolibro cruza fronteras y perdura en el tiempo. A falta de que las casas editoriales estatales les prestasen atención y les ofreciesen oportunidades, se han atrevido a crear editoriales independientes donde editan, autoeditan y/o coeditan exitosos fotolibros que demuestran lo anquilosado del modelo editorial que a grandes rasgos aún hoy sigue sin darse por aludido. La falta de peso de una tradición editorial de fotografía a seguir ha facilitado un nuevo espacio en el que experimentar con libertad absoluta creando una nueva identidad en total consonancia con otros movimientos de la fotografía global. La apropiación de referencias editoriales ajenas a la fotografía, el acercamiento hacia el libro de artista dejando atrás el anglosajón coffe-table book o la complicidad con diseñadores editoriales con los que colaborar desde fases muy iniciales de los proyectos son algunos ejemplos de ello (2014).

Como vemos, los/as autores/as de estas publicaciones, además del trabajo fotográfico y narrativo del libro, abordan, también creativamente, las labores de producción:

A pesar de la variedad de estrategias seguidas, en general se trata de proyectos auto o parcialmente financiados (a veces a través de campañas de micromecenzgo o de sistemas de previo pedido), con ediciones limitadas o reducidas, numeradas o no, en las que se concede un valor especial al carácter artesanal y físico del resultado final (el libro como objeto) (Vega, 2017, p. 683).

Esto nos lleva a hablar de editoriales fundadas por los propios creadores para canalizar sus propuestas, como 'Ca l'Isidret' (la editorial impulsada por Aleix Plademunt, Juan Diego Valera y Roger Guaus para editar sus propios trabajos), 'Biel Books' (fundada por el artista Gabriel Pericàs), 'Fuego Books' (gestionada por el fotógrafo Gustavo Alemán y su hermana Ángela), 'Ediciones Anómalas' (creada en 2012 por Montse Puig, a la cual se uniría el fotógrafo Israel Ariño en 2013), 'Lindero Libros' (plataforma de auto publicación de la diseñadora Noe Lavado y la fotógrafa Helena Rovira), 'Phree' (editorial especializada en fotografía documental dirigida por Juan Valbuena), 'Fiesta Ediciones' (gestionada desde 2009 por la diseñadora Natalia Troitiño y el fotógrafo Ricardo Cases), 'Caravanbook' (fundada por la especialista en turismo

4. En este caso se trata de una escuela público-privada, fruto de la colaboración entre el Ayuntamiento de Alcobendas y PhotoEspaña. 
Virginia Ortega y la fotógrafa Ana Zaragoza) o 'Riot Books', tras la que se encuentran Ilkin Huseynov y Verónica Fieiras.

Junto a estas plataformas de reciente creación surgen otras como 'Dalpine' (en 2010, gracias a José Manuel Suárez y Sonia Berger), editorial y tienda on line especializada en libros de fotografía autoeditados e independientes, y todas ellas se unen a otras que, como la editorial RM, no estando especializadas en fotolibros le han dedicado una especial atención.

En esta revitalización del fotolibro que está teniendo lugar en España es imprescindible referirse a los 'Cuadernos de la Kursala', se trata de una colección de publicaciones, iniciada en 2007, gracias a la propuesta que Jesús Micó realizó a la Universidad de Cádiz. La institución quería poner en marcha una sala de exposiciones especializada en fotografía y, con el asesoramiento de Micó, las muestras que tienen lugar en la sala se complementan con un fotolibro desarrollado por el/la autor/a, por lo que son proyectos capaces de funcionar tanto en formato expositivo como editorial, más allá de ser un simple catálogo-resumen. Esta visionaria apuesta de Micó (recordemos que estamos hablando de 2007, antes de que naciera la «moda» del fotolibro) por este formato se debió, además de creer en sus posibilidades como vehículo óptimo para el discurso fotográfico, a la ubicuidad de este tipo de publicaciones:

nuestra estrategia de promoción extra local sólo podría depender de las publicaciones. Si quienes conforman el núcleo central de poder del arte contemporáneo español no iban a venir a visitar nuestra sala (así como tampoco una audiencia mayoritaria), entonces seríamos nosotros los que cada dos meses viajaríamos puntualmente hasta ellos/as presentándonos en sus manos (humilde pero insistentemente) en forma de foto libros con un marcado carácter de autor, unos volúmenes muy personales que romperían con la concepción (y función) tradicional de un catálogo de exposición. Nuestra colección, Los Cuadernos de la Kursala, sería nuestro único pasaporte para entrar en el sistema del arte actual español, para llegar a una audiencia avanzada (Micó, s. f.).

Por el proyecto Kursala han pasado algunos de los nombres imprescindibles del fotolibro español actual, como Cristina de Middel, Juan Valbuena o Ricardo Cases, entre otros/as. No en vano de Middel es autora del fotolibro español más exitoso de los últimos años: 'The Afronauts' (2012). El proyecto, nacido en la Kursala, narra la historia (real, aunque un tanto increíble) del programa espacial ideado por el gobierno de Zambia en 1964. El libro, tras ser elogiado por Martin Parr, pasaría de venderse por $35 €$ a subastarse por 2.200 (Collera, 2015) y sería finalista en los premios que otorga la feria 'Paris Photo' en la categoría de mejor primer fotolibro. Ya en 2013 fue nominado a 'Deutsche Börse' y ganó el 'Infinity Award' que concede el 'International Center of Photography' de Nueva York.

Otros foto libros españoles recientes que han recibido premios internacionales son: 'Karma' (RVB Books/Dalpine, 2013), de Óscar Monzón (obra ganadora de 'The Paris Photo-Aperture Foundation First Photobook Award' 2013), que plantea una reflexión sobre el sobre el interior de los vehículos como espacio de estudio de las relaciones humanas, 'C.E.N.S.U.R.A.' (Editorial RM, 2011), de Julián Barón (premiado en la categoría abierta-series del primer concurso internacional coorganizado por la agencia Magnum y la web Lens Culture), un conjunto de fotografías de políticos españoles implicados en casos de corrupción quemadas por un exceso de flash, o 'Paloma al aire' (autoedición, 2011), de Ricardo Cases (seleccionada por el 'British Journal 
of Photography' como una de las publicaciones del año), que trata las carreras de palomas en las regiones españolas de Valencia y Murcia como acto simbólico.

La lista de foto libros españoles recientes dignos de mención podría ser casi infinita: 'You Haven't Seen Their Faces' (Riot Books, 2015) de Daniel Mayrit, los retratos de las 100 personas más influyentes del ámbito económico de Londres, todos desconocidos/as para el gran público; 'Ustedes, los vivos' (Dalpine, 2018) de David Hornillos, que documenta un terreno baldío en el que hubo un cementerio cercano a la estación de Chamartín como actual zona de tránsito, o los collages digitales de 'The Random Series' (RM, 2014), de Miguel Ángel Tornero (Premio a los libros mejor editados convocado por el Ministerio de Cultura, sección libros de arte), serían solo tres ejemplos. 'Ser sangre', de Iñaki Domingo, 'Everything will be ok', de Alberto Lizaralde, 'The PIGS', de Carlos Spottorno, 'Sevilla, Semana Santa', de David Jiménez, 'Kosmos', de Marta Bisbal, o 'Yolanda', de Ignacio Navas, podrían ser otros.

Como reflexión final, apuntaremos que sería deseable que la bonanza actual del fotolibro se convierta en una consolidación de largo recorrido, que no sea una burbuja a punto de estallar, especialmente en un país como este, tan propenso a los excesos. En palabras del editor y fotógrafo Juan Valbuena (citado en Fanjul, 2015), ahora hay "mejores proyectos, más editoriales, más repercusión y visibilidad", pero "Lo único que me preocupa es que no podamos generar un mercado y no seamos capaces de tener mayor número de puntos de venta y compradores que nos permitan escapar de la endogamia».

\section{Conclusiones}

Las publicaciones con fotografías como elemento principal nacen a mediados del siglo XIX, prácticamente con la fotografía misma, evidenciando desde un primer momento las posibilidades de este binomio. En aquellos tiempos pretéritos la producción es artesanal y la distribución reducida, y más que de foto libros quizá deberíamos hablar de álbumes ilustrados. Ya en el siglo XX, la expansión de este formato no conoce límites, favorecido por los avances técnicos y por el gusto de los/as autores/as.

Pero, en los comienzos del siglo XXI, la aparición de la tecnología digital pareció amenazar los soportes tradicionales, debido a una rápida y masiva implantación de Internet y las llamadas nuevas tecnologías, canalizando la imagen fotográfica hacia formas virtuales de producción y difusión, como los programas de retoque fotográfico y las redes sociales. Sin embargo, y de manera un tanto paradójica, tras unos años de cambios vertiginosos, en la actualidad el formato libro y el soporte papel son medios altamente apreciados tanto por los/as autores/as como por el público, así como por los/as especialistas. En este sentido, podemos constatar como la popularización de la imagen digital y la saturación icónica de las redes sociales han provocado una nostalgia de lo tangible y, con ello, de los libros y el papel, poniendo en valor al mismo tiempo otras formas más sosegadas y profundas de ver y pensar la imagen fotográfica.

No obstante, esto no quiere decir que un soporte sea mejor que otro, lo realmente importante es que la convivencia entre formatos no solo es posible, sino que es deseable, puesto que tanto los sistemas digitales como los soportes tradicionales poseen sus características especificas que los hacen diferentes entre sí y, por lo tanto, no excluyentes. En el ámbito concreto que nos ocupa podemos decir, por ejemplo, que gracias a la expansión de la tecnología digital se han generado técnicas de maquetación, 
impresión y distribución de foto libros que han impulsado la recuperación masiva de este formato, ofreciendo una serie de posibilidades (como las tiradas de unos pocos ejemplares o unos precios muy ajustados) que no permitían las imprentas tradicionales. Del mismo modo, Internet y las redes sociales también han demostrado ser herramientas muy eficaces a la hora de divulgar y comercializar el trabajo plasmado en un fotolibro.

Sin embargo, es necesario remarcar un conjunto de especificidades y ventajas que el soporte papel presenta respecto a los sistemas digitales, como por ejemplo las características físicas inherentes a toda publicación impresa (tipo de impresión, gramaje del papel, tamaño del libro, etc.), elementos con capacidad para enfatizar o potenciar el trabajo fotográfico y, por lo tanto, nada desdeñables. De la misma forma, el formato libro permite al autor/a crear una obra que, aunque esté formada por un conjunto de varias imágenes, tenga una estructura determinada y un discurso muy concreto, y que estos le sobrevivan, algo muy difícil de conseguir mediante los medios digitales o una exposición. Igualmente, los libros en papel no son necesariamente más contaminantes que los electrónicos, ya que los primeros, una vez impresos, no consumen energía alguna, además de estar exentos de materiales altamente contaminantes, cosa que sí ocurre con cualquier dispositivo digital.

En España, como en otros países, también es fácil constatar este auge del fotolibro, a pesar de que, hasta fechas recientes, ha sido un formato marginal en nuestro país. Este boyante momento es debido a un conjunto de factores, entre los que podemos destacar tanto a una excepcional generación de autores/as muy bien preparados (los cuales están cosechando un notable éxito dentro y fuera de España) como a diversos proyectos, en su mayoría de carácter privado, como ferias, exposiciones, premios, blogs y webs, junto a un verdadero boom de la auto publicación y las editoriales independientes.

Por todo ello podemos decir que la robustez actual del fotolibro, no solo en España sino también a nivel internacional, excede el carácter de una moda pasajera, apareciendo ante nosotros un futuro en el que el fotolibro queda configurado como una opción de primer nivel, a la altura de cualquier otra. Esta toma de conciencia en torno al fotolibro lo introduce, con carácter retroactivo, en la historia de la fotografía, una situación ejemplificada en la aparición de publicaciones recientes como 'The Photobook. A History', de Martin Parr y Gerry Badger (Phaidon, 2004, 2009 y 2014) o 'El Fotolibro Latinoamericano' (editorial RM, 2011) de Horacio Hernández, las cuales evidencian la importancia histórica del fotolibro.

\section{Referencias}

Arjona, D. (26 de marzo-1 de abril, 2010). El libro digital en su laberinto. El Cultural, pp. 8-11.

Bianchi, S. (24 de abril, 2016). Afición y militancia: el fanzine resiste como objeto artístico. elconfidencial.com. Recuperado de https://www.elconfidencial.com/cultura/2016-04-24/ aficion-y-militancia-la-resistencia-del-fanzine-como-objeto-artistico_1188387/

Collera, V. (31 de enero, 2015). Foto libros: enfoca, dispara, edita. elpais.com. Recuperado de https://elpais.com/cultura/2015/01/28/babelia/1422446966_947069.html

Cuevas, D. (mayo de 2017). Fenómeno fotolibro. jotdown.com. Recuperado de http://www. jotdown.es/2017/05/fenomeno-fotolibro/

Doctor Roncero, R. (2013). Pensar el mundo. En R. Doctor Roncero (Dir.). Arte español contemporáneo (1992-2013). Madrid: La Fábrica. 
Fanjul, S. (5 de junio, 2015). Renace el fotolibro. elpais.com. Recuperado de https://elpais.com/ ccaa/2015/06/04/madrid/1433435386_138014.html

Fernández, H. (2017). La Biblioteca es el museo. En Fenómeno Fotolibro [tomo n4, catálogo de exposición]. Barcelona: Fundación Foto Colectania-Centro de Cultura Contemporánea de Barcelona.

Fernández, H., Gimeno, E., Uriarte, J. y de Middel, C. (2014). LIBRO. Un ensayo acerca del libro de fotografía y de su momento actual en España. Barcelona: Fundación Foto Colectania.

Fernández, H. (2011). El fotolibro latinoamericano. México D.F.-Barcelona: RM.

Fontcuberta, J. (2000). La fotografía catalana de 1900 a 1940. En Introducción a la Historia de la Fotografía en Cataluña (pp. 61-84). Barcelona: Lunwerg.

Goikoetxea, N. (2009). De la feria al salón, ¿del salonísmo a la feria? Film und Foto, III (9), pp. 18-23.

Gómez, R., García, A., Cordón, J. A. y Alonso, J. (2016). Leyendo entre pantallas. Gijón: Trea.

Gómez Isla, J. (2005). Fotografía de creación. San Sebastián: Nerea.

González Reyero, S. (2007). La fotografía en la arqueología española (1860-1960). 100 años de discurso arqueológico a través de la imagen. Madrid: Universidad Autónoma de MadridReal Academia de la Historia.

Hoy Es Arte (1 de octubre, 2018). Los libros digitales ya representan el 30,6\% de la producción editorial total. boyesarte.com. Recuperado de https://www.hoyesarte.com/politica/los-libros-digitales-ya-representan-el-306-de-la-produccion-editorial-total_256967/?utm_source=Boletin_20181001_1541\&amp;utm_medium=boletin\&amp;utm_campaign=boletin

Johnson, W., Rice, M. y Williams, C. (2010). Historia de la fotografía. De 1839 a la actualidad. Colonia: Taschen.

López Mondejar, P. (1999). 150 años de fotografía en España. Barcelona: Lunwerg.

Meseguer, R. (2008). Luna Cornata. Recetario analógico-digital de los procesos fotosensibles y sus combinaciones pictóricas. XIX-XXI. Murcia: Consejería de Cultura de la Región de Murcia-Ediciones Tres Fronteras.

Micó, J. (s. f.). Cuadernos de la Kursala. revistaojosrojos.com. Recuperado de http://www.revistaojosrojos.com/cuadernos-de-la-kursala/

Museo Nacional Centro de Arte Reina Sofía (2013). Libros que son fotos, fotos que son libros [Hoja de sala]. Madrid: Museo Nacional Centro de Arte Reina Sofía.

Picazo, G. (2018). Pulsión de archivo en los libros de artista. En P. Vicente y J. Gómez-Isla (eds.), Álbum de familia y prácticas artísticas. Relecturas sobre autobiografía, intimidad y archivo (pp. 177-188). Huesca: Diputación de Huesca.

Sánchez Vigil, J. M. (2013). La fotografía en España. Otra vuelta de tuerca. Gijón: Trea.

Sánchez Vigil, J. M. (2007). Del daguerrotipo a la Instamatic. Autores, tendencias, instituciones. Gijón: Trea.

Sánchez Vigil, J. M. (2006). El documento fotográfico. Historia, usos, aplicaciones. Gijón: Trea.

Uriarte, J. (18 de junio, 2014). El Fotolibro: Aquí y Ahora. fotocolectania.wordpress.com. Recuperado de https://fotocolectania.wordpress.com/category/exposiciones/fotolibros-aqui-yahora/

Vega, C. (2017). Fotografía en España (1839-2015). Historia, tendencias, estéticas. Madrid: Cátedra.

Vega, C. (2016). Reciclando imágenes. Revisión del álbum familiar y de la fotografía vernácula en el fotolibro contemporáneo. En J. C. Alfeo y L. Deltell (eds.), La mirada mecánica. 17 ensayos sobre la imagen fotográfica (pp. 29-41). Madrid: Fragua. 